\title{
Desafios do cooperativismo na cadeia da reciclagem: um olhar a partir da experiência dos catadores
}

\author{
Challenges of cooperatives in the recycling chain: a view from the experience of the \\ waste pickers
}

\author{
Rosina Pérez Menafra ${ }^{1}$
}

Artigo recebido para publicação em jan./2015 e aceito para publicação em mar./2015

\section{RESUMO}

Este artigo discute os desafios que enfrenta o cooperativismo de catadores a partir de entrevistas com trabalhadores que coletam recicláveis de forma organizada em Maceió, capital do estado de Alagoas. Explora de que maneira as transformações no contexto de atuação dos catadores e a lógica coletiva de trabalho em cooperativas se traduzem na sua experiência, para refletir sobre as possibilidades do cooperativismo como ferramenta capaz de reverter o padrão excludente sobre o qual se sustenta a cadeia da reciclagem. As entrevistas revelam que, embora nas cooperativas ocorra um processo de reconfiguração do trabalho e de ressignificação da profissão de catador, a desqualificação social da categoria, a vivência de situações frequentes de humilhação e violência simbólica, a ausência de proteções sociais e a baixa retribuição econômica, colocam entraves à construção de um sentimento de pertencimento, à apropriação da experiência por parte dos catadores e à consolidação de um espaço coletivo organizado. Por fim, reflete sobre a necessidade de combinar ações de fomento do cooperativismo de catadores com outro tipo de medidas de regulação do mercado, buscando impactos na estrutura da cadeia produtiva da reciclagem, uma cadeia injusta sustentada na exploração dos catadores.

Palavras-chave: Cooperativismo de Catadores de Materiais Recicláveis; Cadeia da Reciclagem; Desigualdades Sociais; Sociologia das associações.

\section{ABSTRACT}

This paper discusses the challenges that waste pickers cooperatives face through interviews with workers that collect recycling materials as an organized category in Maceió, capital of the state of Alagoas. Explores how the transformations in the context of performance and the collective logic of work in cooperatives affect their experience, to reflect about the possibilities of cooperativism as a tool to reverse the excluding pattern in which the recycling chain sustains. The interviews reveal that, even with a process of reconfiguration and ressignification of the activity inside the cooperatives, the social disqualification of the category, the frequent situations of humiliation, symbolic violence, absence of social protections and low economic retribution hinder the construction of a sense of belonging, the appropriation of the experience and the consolidation of an organized collective space. Lastly, reflects about the necessity of combining actions to strengthen the waste picker cooperatives with other type of measures of market regulation, looking for the transformation of the recycling chain, an unjust chain based on the exploration of the waste pickers.

Keywords: Waste Pickers Cooperativism; Recycling Chain, Social Inequalities; Sociology of associations.

\footnotetext{
${ }^{1}$ Socióloga. Doutoranda do Programa de Pós-Graduação em Sociologia e Antropologia da Universidade Federal de Rio de Janeiro. Pesquisadora extensionista do Núcleo de Solidariedade Técnica da Universidade Federal de Rio de Janeiro. Áreas de interesse: sociologia do trabalho, desigualdades sociais, gestão integrada de resíduos sólidos, reciclagem, cooperativas de catadores de materiais recicláveis. Endereço: Universidade Federal de Rio de Janeiro / Av. Athos da Silveira Ramos, 149 - Centro de Tecnologia. Salas ABC112 e F122. Cidade Universitária - Ilha do Fundão, Rio de Janeiro. Email: perezmenafra@gmail.com
} 


\section{INTRODUÇÃO}

Este artigo trata dos desafios que enfrenta o cooperativismo de catadores de materiais recicláveis a partir da abordagem de experiências de trabalhadores que coletam recicláveis de forma organizada em Maceió, capital do estado de Alagoas. Procura analisar de que forma as transformações do contexto de atuação dos catadores se traduzem na sua experiência de trabalho, usando o conceito no sentido dado por François Dubet (1996) como construção -individual ou coletiva- do sentido das práticas e condutas, no seio de uma multiplicidade de princípios de ação, em concordância com um percurso biográfico ou trajetória social.

Nos últimos anos, as cooperativas de catadores vêm recebendo incentivos através de políticas públicas e de uma legislação favorável que promoveu avanços significativos no setor da reciclagem. As cooperativas são visualizadas como ferramentas de inserção social e produtiva, que podem oferecer melhores condições de trabalho e aumento de renda a trabalhadores que se encontram numa situação paradoxal: contribuem com o meio ambiente e a sociedade através de uma atividade fundamental como é a reciclagem, trabalhando em condições extremamente precárias e de risco para sua saúde e integridade física e social, numa cadeia produtiva injusta que os exclui da maior parte dos lucros obtidos.

A partir de resultados de uma pesquisa realizada em Maceió em 2010, no marco de uma dissertação de Mestrado em Sociologia pela Universidade Federal de Alagoas, busca contribuir no debate sobre o lugar que pode ocupar o cooperativismo e a organização dos catadores na reversão do padrão excludente sobre o qual se constituiu a cadeia da reciclagem no Brasil. Defende para isso uma abordagem centrada na análise dos empreendimentos e nas relações sociais associativas, tendo como pano de fundo os elementos contextuais, culturais e biográficos presentes nas trajetórias dos seus trabalhadores. Neste sentido, considera que as acumulações de experiências anteriores e percursos biográficos podem ajudar a entender o funcionamento das cooperativas, a maneira como as transformações são vivenciadas e as possibilidades de incorporação de lógicas mais solidárias e horizontais de trabalho. 
Revista Tecnologia e Sociedade, Curitiba, v. 11, n. 22, 2015

Edição Especial XII Encontro Nacional de Engenharia e Desenvolvimento Social

ISSN (versão online): 1984-3526

ISSN (versão impressa): 1809-0044

Foram utilizados conceitos e reflexões da "sociologia das associações", cujo expoente principal é o Movimento Anti-Utilitarista das Ciências Sociais, também conhecido pela sigla MAUSS. Os vários autores enquadrados nesta perspectiva definem as associações como espaços híbridos de sociabilidade em que se combinam o público e o privado, lógicas primárias e secundárias, afetivas e impessoais na intermediação de interesses individuais e coletivos (LAVILLE, 1997; CAILLÉ, 1998). Entretanto, usa subsídios de pensadores brasileiros como Sérgio Buarque de Holanda (1995) e Roberto da Matta (1991), para contextualizar as premissas da sociologia das associações de forma mais apropriada ao âmbito brasileiro, onde predomina uma dinâmica de desigualdades em que relações hierárquicas e lógicas assimétricas prevalecem como princípios de ação constitutivos da experiência.

A estratégia metodológica utilizada na pesquisa foi eminentemente qualitativa. Foram realizadas nove entrevistas em profundidade com membros da Cooperativa de Recicladores de Maceió (COOPREL), uma entrevista coletiva e observações do processo de trabalho ${ }^{1}$. A metodologia escolhida privilegiou o acesso à subjetividade dos atores envolvidos, partindo do pressuposto de que a análise dos processos de interpretação que realizam os trabalhadores das suas experiências vitais e dos contextos nos quais se inscreve sua ação dão acesso à compreensão que eles têm do mundo e deles próprios.

Antes de abordar a experiência dos catadores, o artigo apresenta um panorama das principais transformações da atividade da reciclagem nos últimos anos. Enumera as mudanças que o trabalho em cooperativas supõe do ponto de vista das relações e dinâmicas de trabalho internas e apresenta a análise de entrevistas em profundidade, examinando a forma em que se reconfigura o trabalho, as condições de exercício da atividade e o significado que traz para os catadores à luz das suas biografias. Por último, tece algumas reflexões sobre políticas públicas de inclusão e cooperativismo de catadores como ferramenta de combate às desigualdades sociais.

\section{TRANSFORMAÇÕES NO CONTEXTO DE ATUAÇÃO DOS CATADORES DE MATERIAIS RECICLÁVEIS}


Revista Tecnologia e Sociedade, Curitiba, v. 11, n. 22, 2015

Edição Especial XII Encontro Nacional de Engenharia e Desenvolvimento Social

ISSN (versão online): 1984-3526

ISSN (versão impressa): 1809-0044

Seguindo estimativas do IPEA (2013) que usam como base dados o último Censo Demográfico do IBGE, no Brasil 387.910 pessoas declararam exercer como atividade principal a coleta e comercialização de materiais recicláveis. Estimativas anteriores (IPEA, 2012) realizadas a partir da Pesquisa Nacional de Saneamento Básico de 2008, mostravam que aproximadamente 30.000 catadores formavam parte de 1.175 cooperativas e associações no Brasil. O que significa que menos de $8 \%$ do total de catadores trabalham de forma associada.

O trabalho realizado pelos catadores atende à demanda da indústria recicladora de papel, papelão, vidro, metais e plástico, por materiais descartados para sua reincorporação ao ciclo produtivo como matéria prima. Configuram-se neste sentido como "trabalhadores emergentes da sociedade de industrialização avançada e de consumo de massa" (STROH, 2009: 15) que transformam resíduos em mercadorias com seu trabalho, constituindo a base de uma cadeia produtiva de grande crescimento e lucratividade nos últimos 30 anos.

Os catadores, cooperativados ou de forma individual, fazem parte de uma cadeia de serviço através da realização da coleta seletiva e da atuação na gestão de resíduos sólidos municipais, e de uma cadeia de valor, a cadeia da reciclagem. $\mathrm{Na}$ cadeia de serviços, cujo ator principal é o setor público municipal que se ocupa da gestão e gerenciamento de resíduos sólidos - seguindo competências estabelecidas na Constituição brasileira de 1988 - inserção dos catadores se dá quase totalmente na informalidade, sem reconhecimento da função que exercem na prática na gestão de resíduos. Na cadeia de valor, a cadeia da reciclagem, os catadores conformam a base, que pode ser representada graficamente como uma pirâmide, cujo vértice é ocupado pela indústria de transformação de papel, metal, plástico e vidro. Entre o vértice e a base existem uma série de agentes atuando como intermediários, todos eles do setor privado: depósitos, sucatas e ferros velhos que se apropriam junto da indústria da maior parte dos lucros.

O trabalho dos catadores consiste em coletar, selecionar, separar, acondicionar, transportar e em ocasiões beneficiar os materiais recicláveis comercializáveis, na maior parte das vezes sem apoio por parte das Prefeituras. A atividade é realizada seguindo diferentes modalidades: mediante coleta e classificação dos materiais descartados pós-consumo nas ruas e lixões ou mediante coleta dos materiais separados na fonte geradora, ou seja, residências, empresas e 
Revista Tecnologia e Sociedade, Curitiba, v. 11, n. 22, 2015

Edição Especial XII Encontro Nacional de Engenharia e Desenvolvimento Social

ISSN (versão online): 1984-3526

ISSN (versão impressa): 1809-0044

instituições que entregam o material às cooperativas ou a programas de coleta seletiva. Alguns catadores usam carrocinhas de tração humana ou animal para carregar o material, realizando o trabalho em condições de informalidade e muitas vezes em situação análoga ao trabalho escravo, quando trabalham para depósitos. Outros separam o material diretamente nos lixões que continuam em operação em inúmeras cidades do Brasil. Nas cooperativas, as formas de coleta diferem, dependendo do grau de estruturação e do apoio de parceiros públicos e privados. Algumas realizam coleta mecanizada, com caminhões ou carroças motorizadas, e outras continuam fazendo coleta mediante tração humana.

A catação de materiais recicláveis é uma atividade desprotegida, exercida em grande medida em condições de precariedade e insalubridade extremas: riscos sanitários, ergonômicos, acidentes, violência física e moral, dentre outros. Também existe um desgaste psicológico pelo forte estigma que a figura do catador continua carregando, inclusive em cooperativas, como veremos na análise das entrevistas.

Nos últimos 15 anos, o contexto institucional e jurídico que envolve a atividade dos catadores se transformou significativamente. Diversos instrumentos legais foram conquistados, em grande medida como resultado da capacidade de mobilização e pressão do Movimento Nacional de Catadores de Materiais Recicláveis (MNCR), criado em 2001. O primeiro passo foi o reconhecimento da profissão de catador no Cadastro Brasileiro de Ocupações em 2002. Em 2003 foi criado o Comitê Interministerial de Inclusão Social dos Catadores de Lixo (que em 2010 adotou a nomenclatura reivindicada pelo MNCR "catadores de materiais recicláveis"). Em 2007 a Lei de Saneamento significou uma melhoria nas condições de participação das cooperativas na coleta seletiva de resíduos sólidos dos municípios brasileiros, já que habilitou as Prefeituras a contratar sem necessidade de licitação. Por último, a conquista mais significativa, a Política Nacional de Resíduos Sólidos e sua regulamentação em 2010, deram um lugar de protagonismo às cooperativas e associações de catadores de baixa renda na gestão integrada de resíduos sólidos municipais. A gestão integrada de resíduos com um viés social de inclusão de trabalhadores precários constitui um dos traços mais destacados da política, que tem se tornado uma referência internacional neste sentido.

De forma paralela aos avanços legais e institucionais, o Estado desenvolveu políticas públicas de apoio aos catadores, com investimentos significativos em 
Revista Tecnologia e Sociedade, Curitiba, v. 11, n. 22, 2015

Edição Especial XII Encontro Nacional de Engenharia e Desenvolvimento Social

ISSN (versão online): 1984-3526

ISSN (versão impressa): 1809-0044

capacitação e estruturação de cooperativas. Dados do IPEA (2012) indicam que entre 2007 e 2010 foram introduzidos mais de $R \$ 280$ milhões no segmento, mediante recursos provenientes de diferentes órgãos e instituições do Governo Federal $^{2}$. Dentre os projetos financiados, a maioria objetivou a construção de galpões, aquisição de equipamentos, capacitação de catadores e subsídios a programas municipais de gestão de resíduos com inclusão dos catadores. Em termos gerais, estes instrumentos melhoraram o contexto de atuação das organizações de catadores e valorizaram a profissão. Os investimentos ajudaram a incorporar tecnologia ao processo de coleta e de triagem e a capacitar os quadros de trabalhadores para uma melhor gestão e organização do trabalho. No entanto, mesmo com estímulos, as cooperativas continuam enfrentando dificuldades e desafios, e os catadores permanecem na sua grande maioria obtendo renda insuficiente. Seguindo dados de PANGEA (2006), mais de $60 \%$ das cooperativas apresentam baixa eficiência na coleta e comercialização de materiais recicláveis.

\section{A EXPERIÊNCIA DOS CATADORES E CATADORAS DA COOPREL}

Dentre tantas mudanças identificadas, que ocorre com a experiência dos catadores e suas definições enquanto trabalhadores?

A cooperativa pesquisada, COOPREL, nasceu da reivindicação de exfuncionários da COBEL-Companhia de Beneficiamento de Lixo de Maceió, dependente da prefeitura da capital, como resposta à demissão massiva provocada pela reestruturação do órgão. Foi fundada em 2004, quando 25 trabalhadores pleitearam, além do pagamento dos benefícios que tinham sido negados no desligamento, recursos para garantir o sustento futuro mediante a instalação de uma cooperativa de catadores de materiais recicláveis. Depois de inúmeras negociações e mobilizações, a prefeitura garantiu o aluguel mensal do galpão de $900 \mathrm{~m}^{2}$, e 10 carroças de tração humana para iniciar a coleta dos materiais.

A cooperativa encontra-se localizada no bairro da Serraria, em Maceió, e atua principalmente na região do Tabuleiro dos Martins. A maior parte da coleta é realizada porta-a-porta, mediante carroças que percorrem as ruas da área de influência. A prefeitura empresta o caminhão 3 vezes por semana para coletar os

\footnotetext{
${ }^{2}$ Fundação Banco do Brasil, Ministério das Cidades, Petrobras, BNDES, FUNASA, entre outras (IPEA, 2012).
} 
Revista Tecnologia e Sociedade, Curitiba, v. 11, n. 22, 2015

Edição Especial XII Encontro Nacional de Engenharia e Desenvolvimento Social

ISSN (versão online): 1984-3526

ISSN (versão impressa): 1809-0044

materiais doados por grandes empresas e outras instituições. A captação e sensibilização de doadores de material são realizadas pelos cooperados, que percorrem os bairros pedindo a colaboração dos moradores na separação dos resíduos recicláveis. No ano 2006 a cooperativa recebeu equipamentos para melhorar o processo de separação e estocagem dos materiais: prensa, esteira e balança, por intermédio de um projeto financiado pelo Banco do Brasil, em cuja formulação participou a Universidade Federal de Alagoas. Levou um tempo para que começassem a usar efetivamente as máquinas, mas o resultado foi uma melhoria no uso do espaço do galpão e um aumento no preço de venda dos recicláveis.

No momento de realização do trabalho de campo, a cooperativa contava com 20 trabalhadores, dos quais 14 eram homens e 6 mulheres, com funções diferenciais: os homens realizando a coleta na rua e as mulheres no galpão separando o material e organizando a cooperativa. A rotatividade na cooperativa é muito alta: dos 20 cooperados que fundaram a COOPREL somente 2 trabalham na atualidade. O pagamento, realizado mensalmente, não alcançava no momento de realização da pesquisa o equivalente a um salário mínimo, que na época era de 510 $\mathrm{R} \$$.

\section{RECONFIGURAÇÃO DO TRABALHO, RUPTURA DO ESTIGMA E PROTEÇÃO}

De forma geral o trabalho em cooperativas $^{3}$ supõe uma nova lógica de sociabilidade ditada pelo coletivo, que transforma a dinâmica de trabalho dos catadores, principalmente se comparada à catação em lixões ou nas ruas da cidade ou a outros trabalhos desempenhados de forma individual. A maior escala das cooperativas exige novas funções, como o trabalho com equipamentos de beneficiamento de material reciclável (prensa, balança, empilhadeira), atividades de planejamento e organização do trabalho, gestão financeira e administrativa, captação de doadores, dentre outras. Começa a existir uma divisão do trabalho que transforma o exercício da atividade e as relações entre catadores. A rotina e as

\footnotetext{
${ }^{3}$ Muitas das transformações observadas também foram constatadas em outra cooperativa de Maceió, a COOPVILA - Cooperativa de Catadores da Vila Emater, a partir da experiência de trabalho na equipe técnica da Ong Centro de Educação Ambiental São Bartolomeu durante três anos, num projeto de fortalecimento da cooperativa. A COOPVILA é uma cooperativa de catadores constituída por trabalhadores que atuavam no antigo lixão da cidade, desativado em Maio de 2010.
} 
Revista Tecnologia e Sociedade, Curitiba, v. 11, n. 22, 2015

Edição Especial XII Encontro Nacional de Engenharia e Desenvolvimento Social

ISSN (versão online): 1984-3526

ISSN (versão impressa): 1809-0044

formas de exercer o trabalho são prescritas e definidas pelo grupo e não mais diretamente pelo catador e existe uma interação e um vínculo com novos atores, que passam a formar parte do dia a dia da cooperativa.

Esse contexto tem um efeito sobre as percepções e definições que os catadores realizam sobre seu trabalho e sobre o lugar na cooperativa, demandando respostas que nem sempre formam parte do repertório de práticas e condutas disponíveis, ou que provocam a reformulação e ressignificação de velhas referências. Assim, a experiência anterior de cada catador se vê interpelada ou problematizada, podendo criar tensões e conflitos que se manifestam na subjetividade dos trabalhadores e na capacidade do grupo de estabelecer interesses e objetivos em comum e de atuar de forma coordenada.

A relação com terceiros, envolvidos na atividade de trabalho dos catadores como fornecedores de material reciclável é a que mais se modifica, ou seja, com as residências, comércios e empresas geradoras do resíduo, que separam o material reciclável para entregar às cooperativas. Isto supõe uma transformação fundamental porque na rua ou no lixão os catadores procuravam os materiais no resíduo já descartado. Tinham que "mexer no lixo", ficando em contato com a sujeira e com materiais em estado de decomposição. A fala de uma catadora de 26 anos, mãe de três filhos, é reveladora neste sentido:

Lá (no lixão) a gente, calçava bota, botava um casaco, botava um pano no rosto, um gancho e um saco e todos os materiais que era para reciclar a gente reciclava. Agora, só que aqui é melhor, que aqui é mais limpo, e lá trabalhava junto com cavalo morto, às vezes até criança, aborto a gente achava, pedaço de mão, agulha, muita coisa nojenta, tudo misturado (...)porque lá era tudo nojento e aqui não. Aqui é mais limpo, aqui tem que ser todo unido no dia a dia, para trabalhar, para resolver alguma coisa tem que reunir todo mundo, é importante o trabalho da cooperativa.

$\mathrm{Na}$ cooperativa os catadores têm cronogramas de coleta semanais nos bairros atendidos, que os obriga a interagir de forma mais regular com o "povo da rua" que às vezes respeita e valoriza o catador e às vezes o humilha e degrada. A rua constitui o espaço que os coloca frente a frente com as alteridades que ajudam a defini-los, projetando tanto imagens positivas quanto negativas. É onde o catador enfrenta as categorias e representações vigentes na sociedade, que de modo geral, Ihe atribuem um estatuto inferiorizado como trabalhador e como ser humano. Embora muitas vezes são desrespeitados, maltratados e humilhados por vizinhos, transeuntes e motoristas, é na rua onde o trabalho adquire uma conotação diferente, 
Revista Tecnologia e Sociedade, Curitiba, v. 11, n. 22, 2015

Edição Especial XII Encontro Nacional de Engenharia e Desenvolvimento Social

ISSN (versão online): 1984-3526

ISSN (versão impressa): 1809-0044

onde potencialmente se opera uma valorização da categoria, expressa na atitude dos moradores que separam o material reciclável e esperam o catador no dia marcado, estabelecendo um vínculo que permite reverter, ainda que de forma muito restrita, a avaliação estigmatizada que recai sobre sua figura, como se desprende da fala de um catador entrevistado, de 55 anos:

(...) De qualquer maneira tem que sair na rua e tem que buscar (o material reciclável), ir na casa do pessoal, ir na casa de um, na casa de outro. Eu mesmo, que nem agora, venho da rua, ai o pessoal já guarda, chega e já está separado. É só perguntar, botar na minha carrocinha e pronto, vir me embora. Ai me empolgo, estou sabendo que o material todo é meu, tem aquele dia certo para eu ir, de 8 em 8 dias eu vou, ai o compromisso do serviço é esse, toda vida foi esse. E o pessoal na rua todo mundo gosta de mim, todo mundo guarda o material.

No entanto, a legitimação e valorização ocasional vinda da rua só é vivenciada por certos catadores que aceitam se submeter a essa instância de "teste" moral. Como resultado, muitos catadores preferem permanecer dentro da cooperativa, resguardados das degradações que frequentemente sofrem realizando a coleta. O caráter de proteção que implica a cooperativa é mencionado por vários catadores, no sentido de constituir um espaço que proporciona melhores condições de trabalho e maior estabilidade do que outras ocupações possíveis. Embora seja considerada pela maioria a última alternativa disponível, ante ocupações que supõem ainda piores condições de trabalho, na rua ou em outros trabalhos extremamente desgastantes do ponto de vista físico, a cooperativa se considera uma espécie de "refúgio". Essa imagem expressa a ambivalência que representa, já que a condição de refúgio evoca ao mesmo tempo um caráter positivo, como lugar onde se encontra asilo, acolhida e amparo, mas também negativo, porque a necessidade de refúgio se vincula a uma situação de perigo ou risco iminente.

A compreensão do significado que a cooperativa tem para os entrevistados se dá de forma mais completa à luz das suas trajetórias de vida. A maioria dos catadores apresenta biografias altamente fragmentadas e instáveis, tanto no que refere a sua inserção laboral quanto a outros vínculos de pertencimento e solidariedade, com percursos que mostram alternância entre atividades formais e protegidas, ocupações precárias no setor informal e períodos de desocupação. A permanente incerteza, tanto do ponto de vista laboral como econômico e social, a ameaça constante derivada da carência de condições para sustentar a família, as experiências extremas do ponto de vista emocional e físico marcam as histórias dos 
Revista Tecnologia e Sociedade, Curitiba, v. 11, n. 22, 2015

Edição Especial XII Encontro Nacional de Engenharia e Desenvolvimento Social

ISSN (versão online): 1984-3526

ISSN (versão impressa): 1809-0044

cooperados. Tudo isso tem um impacto significativo na subjetividade dos trabalhadores, que precisam aprender a lidar com a instabilidade e com a precariedade sempre presentes nas suas biografias. A maior parte dos membros da COOPREL teve que enfrentar transformações extremas, derivadas de momentos de ruptura ou de mudança radical. Nesse contexto, a cooperativa surge como lugar seguro e relativamente confortável de trabalho, sempre percebido, no entanto, como temporário, tanto para os mais jovens, em busca de oportunidades melhores como para os que estão na etapa final das suas trajetórias laborais.

O referencial permanente nos discursos dos cooperados e o horizonte almejado por todos é o trabalho "fichado" em "firma registrada", com carteira assinada e direitos sociais garantidos. A cooperativa pelo contrário, é sinônimo de poucas proteções sociais e renda insuficiente para a manutenção da família. Mesmo assim, se considera um bom lugar de trabalho.

É por isso que eu estou aqui, porque é melhor estar aqui do que sem nada. Aqui só é ruim porque a gente ganha pouquinho, mas se não fosse eu gosto daqui. Gosto daqui porque eu estou tirando meu alimento, o dela (da filha). E se estivesse em casa? Ai quem ia me dar? Meu marido passou oito meses desempregado, se estivesse eu e ele?

\section{VALORIZAÇÃO DOS SABERES E IGUALDADE NA PRECARIDADE: CONSTRUINDO A FRÁGIL IDENTIDADE DE CATADOR}

De forma geral, é possível identificar poucos referentes simbólicos que proporcionem uma base sobre a qual afirmar a identidade de catador, o que dificulta a construção de um sentimento de integração e de articulação de interesses. A desvalorização social da categoria "catador", que se traduz em situações frequentes de humilhação e violência simbólica sofridas na rua, além da ausência de proteções sociais e da baixa retribuição econômica que supõe a atividade, reduz a possibilidade de apropriação da experiência por parte dos trabalhadores.

No entanto, existem alguns referentes sobre os quais é possível construir uma identificação. Um saber prático genérico sobre reciclagem é a base sobre a que se constrói a ainda frágil definição dos catadores enquanto trabalhadores. Além do conjunto de competências comunicativas que permitem conseguir os materiais recicláveis necessários para o funcionamento da organização, existe outro conjunto de saberes altamente valorizado, incorporado através da experiência de trabalho. 
Revista Tecnologia e Sociedade, Curitiba, v. 11, n. 22, 2015

Edição Especial XII Encontro Nacional de Engenharia e Desenvolvimento Social

ISSN (versão online): 1984-3526

ISSN (versão impressa): 1809-0044

Trata-se de um conhecimento que não é adquirido por intermédio da educação formal e que configura o núcleo do que significa "ser catador": é a capacidade de identificação dos diferentes materiais que possuem valor, um saber prático orientado pelo mercado que exige a familiaridade com um conjunto de classificações, códigos e terminologias que delimitam um campo semântico específico.

$\mathrm{Na}$ COOPREL esse conhecimento prévio é uma exigência para aceitar o ingresso de novos cooperados. A identificação dos diferentes tipos de plástico, de vidro, de metal, dentre outros materiais, que são comprados pelos intermediários é uma necessidade ditada pela rotina da cooperativa porque multiplica o valor da venda. Assim, "carina", "plástico mole", "plástico duro" ou "coquinho" são conceitos "nativos" que designam materiais de formas que nem sempre coincidem com a nomenclatura utilizada pela indústria ou pela academia. Sua presença revela a existência de códigos compartilhados pelos catadores, e de alguma forma fornece uma fonte de identificação ao grupo.

Nesse contexto de escassez de referentes simbólicos e de compromissos coletivos fortes, a condição que define a igualdade com os outros cooperados e que unifica a experiência individual e coletiva se fundamenta no compartilhamento de carências, dificuldades e sofrimentos atravessados ao longo da vida. A aceitação das regras do jogo da organização aparece como um meio para viabilizar a finalidade da mesma, que se reduz à geração de uma renda mensal para sobrevivência imediata da família e não a um compromisso em relação ao projeto de formação da cooperativa. Poucos cooperados mostram uma adesão "ideológica" aos princípios do cooperativismo e da economia solidária. O vínculo se fundamenta na necessidade de estabelecer regras mínimas de convivência e de respeito mútuo, gerando laços sociais muito frágeis.

A experiência de vida dos catadores mostra permanentemente a fugacidade das relações sociais e o caráter episódico dos percursos, onde o envolvimento pode ter um custo muito alto do ponto de vista emocional e social. Como resultado, existe uma dificuldade de visualizar interesses em comum além das questões materiais imediatas, pautadas pela lógica da necessidade. De modo geral, o comportamento estratégico dos cooperados se reduz a uma perspectiva de curto prazo, em que se valorizam os ganhos imediatos que não exigem maiores níveis de engajamento. 
Revista Tecnologia e Sociedade, Curitiba, v. 11, n. 22, 2015

Edição Especial XII Encontro Nacional de Engenharia e Desenvolvimento Social

ISSN (versão online): 1984-3526

ISSN (versão impressa): 1809-0044

A maior parte dos cooperados (fora os mais antigos) atribui sua participação na cooperativa à necessidade de inserção laboral e de obtenção de uma renda mensal para sobrevivência da família. Tanto a retribuição econômica quanto as "ajudas" obtidas na coleta, que vão desde móveis, eletrodomésticos e lanches até dinheiro, formam parte dos incentivos identificados pelos cooperados como vantagens do trabalho na cooperativa. Neste sentido, a instrumentalização da identidade se manifesta na utilização da condição de precariedade como recurso em situações de interação na rua, que possibilita "ganhar coisas" que podem levar para suas casas e suas famílias.

Os interesses a serem defendidos em geral se concebem em torno da ideia de "favor", de ajuda e não de "direitos" enquanto trabalhadores e cidadãos. Embora existam reivindicações enunciadas em termos de direitos, predominam as expectativas de retorno de ajudas e favores pontuais e de caráter assistencialista por parte dos interlocutores institucionais da cooperativa. Na maior parte dos casos, o critério a partir do qual se avaliam e mensuram as interações e os apoios, se fundamenta na sensibilidade dos outros de perceber uma situação de carência concreta. O comprador é considerado bom parceiro porque dá elementos para acondicionamento dos materiais recicláveis (arame e nylon) sempre que a cooperativa precisa. $\mathrm{O}$ ex-presidente, mesmo atuando de forma arbitrária na distribuição dos rendimentos da venda do material, era considerado uma boa liderança porque sempre que alguém precisava, adiantava dinheiro.

Em soma, não se evidencia na cooperativa uma orientação coletiva capaz de disputar uma melhoria na posição relativa da mesma, num contexto em que se encontram disponíveis recursos políticos e institucionais na forma de editais e projetos de cooperação e parceria. Mesmo num contexto de oportunidades favoráveis com políticas públicas de apoio à economia solidária e aos catadores de materiais recicláveis, é difícil articular elementos que possam operar como fatores de mobilização. Como resultado, existe uma atomização das estratégias dos cooperados, que se resumem exclusivamente as tentativas de resolução parcial e momentânea da situação de privação material à que estão submetidos.

CONSIDERAÇÕES FINAIS: OS DESAFIOS DO COOPERATIVISMO DE CATADORES 
Revista Tecnologia e Sociedade, Curitiba, v. 11, n. 22, 2015

Edição Especial XII Encontro Nacional de Engenharia e Desenvolvimento Social

ISSN (versão online): 1984-3526

ISSN (versão impressa): 1809-0044

Os resultados apresentados apontam que a experiência de "ser catador" se vê interpelada e reconfigurada no contexto das transformações da atividade. $O$ estímulo à organização em cooperativas e a influência de processos mais abrangentes de reconhecimento da profissão e expansão de políticas de incentivo ao segmento têm provocado mudanças importantes, principalmente na transformação das relações internas e externas e na rotina de trabalho dos catadores. As modificações na forma de trabalho e nas relações sociais presentes na cooperativa têm efeitos sobre a forma em que os catadores se enxergam como trabalhadores e na capacidade de ação coletiva do grupo.

A partir destes resultados espera-se contribuir para uma reflexão mais ampla sobre o papel das políticas públicas de geração de emprego e renda e de estímulo do trabalho associado como mecanismo de combate às desigualdades sociais. Embora as políticas de fomento dos empreendimentos de catadores são fundamentais no fortalecimento da categoria e na expansão e consolidação da reciclagem, o incentivo do cooperativismo e do trabalho associado de catadores deve ser acompanhado de uma série de medidas para tornar mais justa a cadeia de valor e de serviços na que estão inseridos. O magro resultado do ponto de vista da renda gerada para os cooperados contribui na perpetuação de uma situação de instabilidade, rotatividade e atomização do trabalho, que incide na qualidade do serviço prestado, na capacidade de se mobilizar coletivamente por direitos e reconhecimento e nas condições de vida dos trabalhadores e suas famílias. Desta forma, o apoio por parte de prefeitura através da contratação para prestação do serviço de coleta seletiva ao município constitui um complemento essencial aos quase sempre insuficientes resultados da comercialização dos recicláveis.

O cooperativismo, como forma de organização do trabalho e da gestão dos empreendimentos não pode ser pensado como receita automática e universal a ser aplicada em qualquer circunstância, esperando consequências e resultados padronizados em diferentes grupos e contextos. Existem especificidades derivadas de dinâmicas e características do tipo de atividade econômica e dos grupos em questão, que devem ser levadas em consideração.

Para realmente ter um impacto no combate às desigualdades sociais, o fomento do cooperativismo de catadores precisa ser articulado com outras medidas de regulação do mercado, buscando transformações na estrutura da cadeia 
Revista Tecnologia e Sociedade, Curitiba, v. 11, n. 22, 2015

Edição Especial XII Encontro Nacional de Engenharia e Desenvolvimento Social

ISSN (versão online): 1984-3526

ISSN (versão impressa): 1809-0044

produtiva da reciclagem, uma cadeia injusta que se sustenta na exploração dos catadores por intermediários (e indiretamente pela indústria) que trabalham na informalidade e que dominam o mercado baixando o nível geral de preços dos materiais recicláveis.

Neste sentido, nos últimos tempos, diferentes políticas e programas estão investindo no estímulo de redes de cooperativas ou cooperativas de segundo grau, com capacidade de estocar maiores volumes de materiais recicláveis, conseguindo melhores preços e negociação direta com a indústria da reciclagem (RUTKWOSKI, 2013). No entanto, essas redes ainda permanecem restritas a poucos locais do Brasil, congregando cooperativas com maiores níveis de organização e de profissionalização dos quadros de catadores. Um desafio futuro do ponto de vista da pesquisa será o de acompanhar de perto a evolução destas redes, analisando seus impactos na organização interna das cooperativas, na experiência dos catadores e na estrutura da cadeia produtiva da reciclagem.

Como balanço final, considera-se que, mesmo com as dificuldades e os entraves identificados na estrutura atual da cadeia da reciclagem e na viabilidade e sustentabilidade das cooperativas, a consolidação do cooperativismo de catadores é um instrumento importante no fomento da autonomia do segmento frente a outros atores da cadeia. As cooperativas, a partir de uma estrutura mais horizontal e participativa, constituem laboratórios de autogestão, ou seja, espaços de socialização em práticas e relações mais democráticas, o que contribui em médio e longo prazo na multiplicação de experiências de ação coletiva, mais reconhecidas no espaço público, e na capacidade dos catadores de colocar em pauta reivindicações por direitos e promover uma crítica societária mais ampla.

\section{REFERÊNCIAS}

DUBET, François. Sociologia da experiência. Lisboa: Instituto Piaget, 1996.

CAILLÉ, Alain. Don et association. In: La revue du MAUSS semestrielle, no 11 . Une seule solution, l'association? Sócio-économie du fait associative. Paris: La Découverte, 1998.

DAMATTA, Roberto. A casa e a rua. Rio de Janeiro, Guanabara Koogan, 1991

HOLANDA, Sérgio Buarque de. Raízes do Brasil. São Paulo: Companhia das letras, 1995. 
IPEA - Instituto de Pesquisa Econômica Aplicada. Situação social dos catadores e das catadoras de materiais recicláveis. Brasília, IPEA: 2013. IPEA: 2012

Diagnóstico sobre catadores de resíduos sólidos. Relatório de pesquisa. Brasília,

LAVILLE, Jean-Louis. L'association: une liberté propre à La démocratie. In: LAVILLE, J.L. e SAINSAULIEU, R (orgs). Sociologie de l'association. Des organisations à l'épreuve du changement social. Paris: Desclée de Brouwer, 1997.

PANGEA - Centro de Estudos Socioambientais. Análise dos custos de geração de postos de trabalho na economia urbana para o segmento de catadores de materiais recicláveis. Relatório técnico final. Salvador, MNCR: 2006

RUTKOWSKI, Jacqueline. Redes solidárias de catadores e gestão de resíduos sólidos. Revista Tecnologia e Sociedade. V9, no 18. Ano 2013

STROH, Paula (Org). Cidade, lixo e cidadania. Maceió: EDUFAL, 2009 